\title{
The effect of joint configuration on the strength and stress distributions of dissimilar adhesively bonded joints
}

\author{
Armin Yousefi Kanani ${ }^{a}$, Xiaonan Hou ${ }^{\text {a* }}$, Rachael Laidlaw ${ }^{\mathrm{b}}$, Jianqiao Ye ${ }^{\mathrm{a}}$ \\ ${ }^{a}$ Department of Engineering, Engineering Building, Lancaster University, Lancaster, LA1 4YW, UK \\ bDepartment of Mathematics and Statistics, Lancaster University, Lancaster, LA1 4YR, UK \\ ${ }^{*}$ Corresponding author (email address: $\underline{\mathbf{x} . h o u 2 @ l a n c a s t e r . a c . u k)}$
}

\begin{abstract}
:
The recent increase in the use of adhesively bonded joints (ABJs) made from dissimilar adherends demands the acquisition of a better understanding of the strength and behaviour of these joints, including their failure mechanisms. Several studies have reported on such joints individually, however few have compared the performances of dissimilar ABJs with varying configurations and design parameters, in order to determine the optimal design configuration for hybrid structures. In this work, a comparative study using experimental methods and finite element analysis was conducted, focusing on four joint configurations (scarf joints, stepped-lap joints, half-lap splice joints and single-lap joints), with the aim of evaluating the ways in which their performances differ. In addition, the effects of overlap length $\left(L_{0}\right)$ and the mechanical properties of the adherends on the overall success of each joint were particularly closely analysed and compared. The results showed that the scarf joint provided the best performance of all the designs discussed, and it was found that increasing the overlap length was only beneficial for certain joint configurations and adherend combinations. In dissimilar joint, by enlarging overlap length from $12.5 \mathrm{~mm}$ to $25 \mathrm{~mm}$, the failure load increase by $47.50 \%$ and $21.25 \%$ for the scarf and the stepped-lap joints, respectively, while the percentage increase for half-lap splice and single lap joints are less than $10 \%$. Moreover, the mechanical properties of the adherends significantly affected the failure mechanisms of the dissimilar joints, and for all four joint configurations, the failure was initiated by a crack at the adherend-adhesive interface adjacent to the adherend with a lower modulus.
\end{abstract}

Keywords: dissimilar adhesive joint; cohesive damage model; finite element analysis (FEA); strength; Mechanical Testing; joints/joining 


\section{Introduction:}

As a result of the rapid development of new engineering products in recent decades, multi-material structures are now widely used, for which proper joining techniques are critical. Of the joining methods available, adhesive joints attract the most attention, due to their numerous advantages. The use of adhesive enables the development of lightweight parts, preserves surface aesthetics by avoiding galvanic corrosion, is cost-effective and offers a more uniform load distribution for highly integrated structures. Adhesively bonded joints also have several joint configuration possibilities, such as lap joints, butt joints and scarf joints.

A lot of thorough research into the failure of joints made from identical adherends (for example aluminium [1][2][3][4][5][6] and composite [7][8][9][10]) has already been conducted, and the findings are rather well known. However, choosing the correct joint configuration is an extremely challenging task when designing a hybrid structure, due to the differences in the mechanical properties of the constituents, leading to unusual peel and shear stress concentrations at the bond-line edges [11]. In spite of this, very few works [12][13][14][15][16][17][18] focus on the case of dissimilar adherends. Therefore, examining the strength and stress distribution for each joint design when made from two different adherends is essential, as the stress distribution at the two adherend-adhesive interfaces will be different.

In a previous study, Khashaba et al. [19] evaluated the effect of thickness and angle on composite adhesive scarf joints under tensile and fatigue loading. Here, the results showed that decreasing the scarf angle and increasing the thickness of the composite layer decreased the strength of the scarf joint. Additionally, Kumar et al. [20] investigated the tensile failure of scarf joints by putting adherends made of carbon fibre reinforced polymer (CFRP), which were joined with a structural adhesive, under a uniaxial tensile load. The results showed that a scarf angle of less than $2^{\circ}$ resulted in composite failure, while larger angles led to cohesive failure. Later, during an investigation into shear and peel stresses of scarf joints, Silva et al. [21] introduced the direct method to determine parameters for the cohesive zone, which aided in the understanding of the influence of the aforementioned stresses on the failure load of the scarf joint. In this study, three different types of adhesive were tested in joints with aluminium adherends, and it was concluded that the epoxy adhesive was able to withstand the greatest failure load for all scarf angles, due to its higher strength in comparison to the ductile and flexible adhesives.

Furthermore, many investigations have been carried out to evaluate the strength and stress distribution of single-lap joints under various loading conditions: tensile loads [5][22][23][24][25][26][27][28][29] and bending moment loads [30][31][32]. For example, Sawa et al. [14] used the two-dimensional theory of elasticity and the finite element method (FEM) to study the stress distribution of the traditional singlelap joint made from dissimilar adherends, when subjected to tensile loads. Here, the analytical and finite element analysis (FEA) results showed good agreement, and it was found that singularities occur at the 
edge of the bonding interface. Moreover, Pinto et al. [15] performed experimental and analytical studies to explore the tensile strength of single-lap joints using similar and dissimilar adherends bonded with acrylic adhesives. The indirectly-obtained cohesive parameters were validated with the experimental results before being employed in FEA, and the results showed that an increase in the adherends' stiffness caused reduced joint bending, leading to an increase in joint strength. Finally, Stuparu et al. [33] simulated the behaviour and strength of dissimilar aluminium-CFRP single-lap joints by using a combination of Cohesive Zone Modelling (CZM) and eXtended Finite Element Modelling (XFEM). The conclusion drawn was that dissimilar AL-CFRP joints could successfully maintain the assembly stiffness (in contrast to the similar AL-AL joints), but that their strength was reduced by the delamination and pull-out of carbon fibres.

Regarding stepped-lap adhesive joints, Mori et al. [34] investigated joint strength, both experimentally and numerically, by using similar adherends which were subjected to a shear tensile load. The FEA results showed that tensile stress was considerably higher at the edges in both the butt and lap sections of the stepped-lap joint, due to the greater stress concentration at these edges. In another work, Mori et al. [35] studied the effects of geometric designs such as adherend thickness, lap length and step number on the performance of the stepped-lap adhesive joint. Further to this, factors like Young's modulus and the yield strength of the material were examined in relation to joint strength. In addition, Ichikawa et al. used the three-dimensional FEM to analyse the strength and stress distribution of dissimilar steppedlap joints under tensile loading [13] and bending moment loading [36]. It was concluded that the maximum value of stress drops when the Young's modulus of the adhesive or the number of joint steps is increased.

Despite the fact that many studies have been conducted on the strengths and failure mechanisms of various adhesively bonded joints, there are a limited number of studies focusing on dissimilar joints and their performances when compared with bonded joints made from identical adherends. Hence, the main objectives of this work are to carry out a comparative study of four joint configurations, to understand their failure mechanisms and to investigate which is the optimal design for use in hybrid structures. In order to do this, samples of scarf joints, stepped-lap joints, half-lap splice joints and single-lap joints were manufactured with an epoxy adhesive (Loctite EA 9497) and two types of adherend: aluminium (AL) and Polyphthalamide (PPA), giving three different joint combinations: AL-AL, PPA-PPA and AL-PPA. A parametric study was then carried out to investigate the influence of overlap length $\left(L_{0}\right)$ on the strength of the AL-PPA joints in comparison to the AL-AL and PPA-PPA joints. The experimental results were compared with numerical results obtained in Abaqus $^{\circledR}$, in which two layers of CZM elements were used to model the adherend-adhesive interfaces. For the AL-PPA joints, the numerical analysis also consisted of a comprehensive stress analysis for different $L_{0}$ values through the middle of the adhesive layer, as well as a damage analysis which presented the failure process of the dissimilar joints. 


\section{Mechanical Testing}

\subsection{Material Properties}

In this study, two types of adherend were used, one made from aluminium alloy (6082 T6) and the other from polyphthalamide (PPA). The aluminium was provided in bars with a width of $25 \mathrm{~mm}$, length of $5 \mathrm{~m}$ and thickness of $3 \mathrm{~mm}$. The PPA (specifically Grivory HTV-5H1 black 9205) was provided in plate form with a size of $100 \times 100 \times 3 \mathrm{~mm}$, and is a reinforced engineering thermoplastic made of $50 \%$ glass fibre, based on a semi-crystalline, partially-aromatic polyamide. Furthermore, the epoxy adhesive used for this work was Loctite EA 9497, a two-component material of medium viscosity, which cures at room temperature. The properties for the above materials were obtained from previous research [37] through tensile tests, based on the ISO EN 485-2:2004 standard for the adherends and the ISO 527-2 standard for the epoxy adhesive (Table 1).

Table 1: The bulk material properties of the adherends and adhesive [37].

\begin{tabular}{lccc}
\hline Property & Aluminium 6082 T6 & Polyphthalamide & Loctite EA 9497 \\
\hline Young Modulus (GPa) & $70.77 \pm 0.38$ & $17.61 \pm 0.06$ & $7.70 \pm 0.46$ \\
Yield Stress (MPa) & $254.59 \pm 3.20$ & $241.33 \pm 10.4$ & $46.29 \pm 3.13$ \\
Elongation at fracture (\%) & $10.83 \pm 0.95$ & $1.76 \pm 0.04$ & $0.71 \pm 0.09$ \\
Poisson Ratio & $0.30 \pm 0.01$ & $0.32 \pm 0.04$ & $0.29^{\mathrm{a}}$ \\
Density (tonne/mm^3) & $2.7 \times 10^{-9^{\mathrm{a}}}$ & $1.65 \times 10^{-9^{\mathrm{a}}}$ & $1.1 \times 10^{-9^{\mathrm{a}}}$ \\
\hline${ }^{\mathrm{a}}$ Manufacturer's data sheet & & & \\
\hline
\end{tabular}

\subsection{Manufacturing and Testing}

In Figure 1, the geometry and dimensions of the (a) scarf joints, (b) stepped-lap joints, (c) half-lap splice joints (HLP) and (d) single-lap joints (SLJ) are shown. The two adherend types (aluminium and PPA) each had a thickness of $t_{p}=3 \mathrm{~mm}$, while the thickness of the adhesive was $t_{A}=0.2 \mathrm{~mm}$, and in the stepped-lap and half-lap splice joints, the thickness of the vertical adhesive was also $t_{A 1}=0.2 \mathrm{~mm}$. To create steps for the stepped-lap joint, the overlap length was divided into three equal parts $\left(L_{S}=L_{0} / 3\right)$ where the vertical length of each step was $t_{s}=0.78 \mathrm{~mm}$. Contrastingly, the vertical length of each step in the half-lap splice joint was $t_{s}=1.6 \mathrm{~mm}$. Moreover, the angles of the scarf joints $(\alpha)$ were $13.5^{\circ}$, $6.89^{\circ}, 4.59^{\circ}$ and $3.44^{\circ}$, and the lengths of the bond-lines $\left(L_{0}\right)$ for the three other joint types were $12.5 \mathrm{~mm}, 25 \mathrm{~mm}, 37.5 \mathrm{~mm}$ and $50 \mathrm{~mm}$. The parameters here (angle and length of bond-line) are correspondingly comparable, due to the fact that for example an angle of $\alpha=3.44^{\circ}$ on the scarf joint results in the length of the overlap length being around $50 \mathrm{~mm}$.

Table 2: The material combinations used for all four configurations of the joints.

\begin{tabular}{cccc}
\hline ID & Adherend-1 & Adherend-2 & Adhesive \\
\hline AL-AL & Aluminium & Aluminium & Loctite EA 9497 \\
\hline AL-PPA & Aluminium & PPA & Loctite EA 9497 \\
\hline PPA-PPA & PPA & PPA & Loctite EA 9497 \\
\hline
\end{tabular}


For all four joint configurations, the adherends were bonded together using an epoxy adhesive, giving three possible material combinations: AL-AL, PPA-PPA, and AL-PPA (Table 2). A total of 192 specimens were made to study the effects of adherend stiffness and overlap length on the performance the adhesively bonded joints, depending on their configuration.
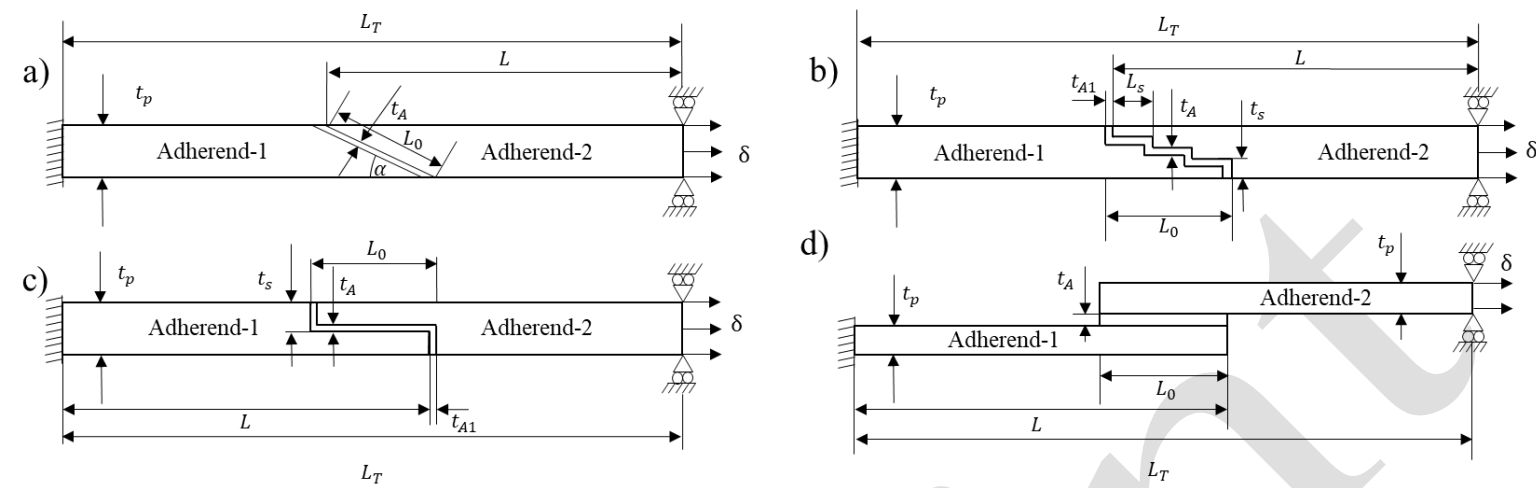

Figure 1: The joint configurations of (a) scarf joint, (b) stepped-lap joint, (c) half-lap splice joint and (d) single-lap joint.

The manufacture of the specimens began with the cutting of the adherends into their final dimensions $(L=100 \mathrm{~mm}$ ), and the CNC XYZ $750 \mathrm{HD}$ machine was used to make the final shape of the scarf joints, stepped-lap joints and half-lap splice joints. For all joint designs, the same surface preparation method was implemented in order to increase bonding strength. This involved three steps: firstly, the bonding surfaces were grit blasted with a Grade 12 Guyson Metallic Blast Medium (corresponding particle size of 150-250 microns), before being cleaned with compressed air in order to remove any extra dust created during the blasting process. Then, the bonding surfaces were cleaned once again with acetone and Loctite SF 706. For the single-lap joints, fixtures were used to guarantee proper alignment, as well as to control the adhesive thickness and overlap length. End tabs were also used for this joint type, to improve alignment in the tensile test machine. On the other hand, no fixtures were required for the scarf joints, stepped-lap joints and half-lap splice joints due to the design of these adherends resulting in natural alignment. For all joints, a wire spacer with a thickness of $0.2 \mathrm{~mm}$ was used to control the thickness of the bond-line, and the curing process of the adhesive was done at room temperature for seven days. 

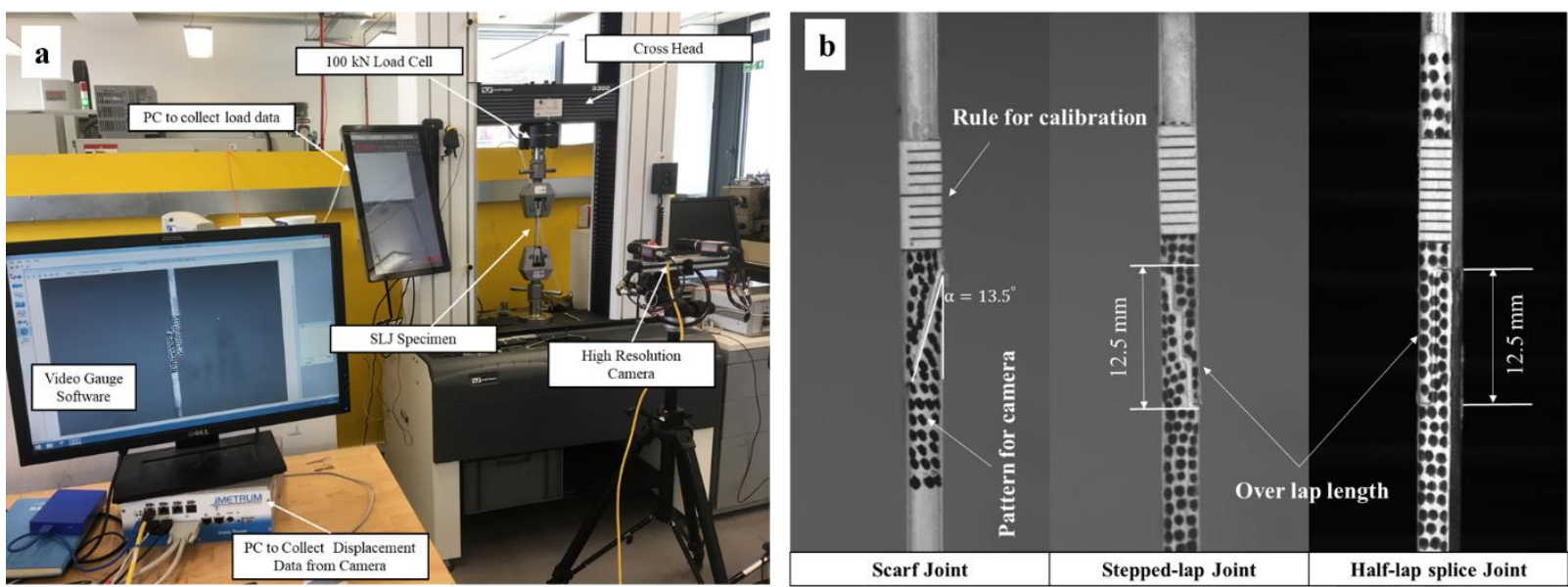

Figure 2: (a) The tensile test setup for an SLJ with a non-contact measurement system and (b) joint samples with an overlap length of $L_{0}=12.5 \mathrm{~mm}$.

The tension test was conducted at room temperature, using an Instron 3380 series machine with a $100 \mathrm{kN}$ load cell, where the specimen was under a displacement control of $0.5 \mathrm{~mm} / \mathrm{min}$ (Figure $2 \mathrm{a}$ ). To measure the displacement, a non-contact video method using the Imetrum System was adopted, for which all specimens were covered with black and white dots of diameter $0.3 \mathrm{~mm}$, to create a speckled pattern on the specimens' surface. The dots were then tracked by the camera, and the original pattern was used as a reference image, to which the other images were compared. When calibrating the camera, the paper rule was used (Figure 2b).

\section{Finite Element Analysis}

\subsection{FEA Modelling}

Numerical models for the four different joint configurations were built in Abaqus ${ }^{\circledast}$, which provided both the stress distribution and the damage variable along the bond-line for various values of overlap length $\left(L_{0}\right)$, while also predicting the joint strength. The explicit two-dimensional non-linear solver was utilised to compensate for the rapid crack growth along the bond-line of the epoxy adhesive.

Two different cases were analysed. In Case 1, joint strength was predicted using CZM. In Case 2, the stress distribution along the bond-line was analysed (without the use of CZM). For the first case, the adherends (AL and PPA) were treated as elastic isotropic materials (Table 1), modelled by CPE4R plane strain elements. In the special case of the tapered bonded edges of the scarf joint, CPE3 plane strain elements were used. The adherend sections in the bonded area were meshed with elements of size $0.05 \mathrm{~mm} \times 0.05 \mathrm{~mm}$, and for the outer sections, the bias effect was used with a minimum size of $0.05 \mathrm{~mm}$ and a maximum size of $1 \mathrm{~mm}$, to reduce the computational time (Figure 3-5). Furthermore, the adhesive section was divided into three layers. Two of these (namely Path 1 and Path 2, located adjacent to each adherend) were meshed using cohesive elements (COH2D4) of thickness $0.05 \mathrm{~mm}$, to model the interactions between the adhesive and Adherends 1 and 2 respectively (Table 3 ). In between 
those layers was a third layer, meshed by CPE4R plane strain elements of thickness $0.05 \mathrm{~mm}$, as illustrated in Figure 3-5.

Table 3: The cohesive layer interface properties for the FE models of the adhesively bonded joints depending on the adherend combination

\begin{tabular}{ccc}
\hline ID & Path 1 (Interface Property) & Path 2 (Interface Property) \\
\hline AL-AL & AL/adhesive & AL/adhesive \\
\hline AL-PPA & AL/adhesive & PPA/adhesive \\
\hline PPA-PPA & PPA/adhesive & PPA/adhesive \\
\hline
\end{tabular}

For the AL-AL and PPA-PPA joints, the same CZM properties were defined in both Paths 1 and 2, as the top and bottom adherends were made of identical materials. However, in the AL-PPA joint, Path 1 had the properties of the AL-adhesive interface, while Path 2 had those of the PPA-adhesive interface. These properties include elasticity, plasticity and susceptibility to damage.

Table 4: The CZM parameters for Loctite EA 9497 at each interface [37].

\begin{tabular}{lcc}
\hline Property & $\begin{array}{c}\text { Loctite EA 9497 } \\
\text { AL-Adhesive Interface }\end{array}$ & $\begin{array}{c}\text { Loctite EA 9497 } \\
\text { PPA-Adhesive interface }\end{array}$ \\
\hline $\mathrm{G}_{\mathrm{n}}(\mathrm{N} / \mathrm{mm})$ & $0.26 \pm 0.06$ & $0.22 \pm 0.04$ \\
$\mathrm{G}_{\mathrm{s}}(\mathrm{N} / \mathrm{mm})$ & $0.90 \pm 0.38$ & $0.46 \pm 0.09$ \\
$\mathrm{t}_{\mathrm{n}}(\mathrm{MPa})$ & $25.35 \pm 10.26$ & $20.94 \pm 7.27$ \\
$\mathrm{t}_{\mathrm{s}}(\mathrm{MPa})$ & $16 \pm 5$ & $10 \pm 3.75$
\end{tabular}

Table 4 shows the CZM parameters obtained in previous research [37] for Loctite EA 9497 from the AL-AL and PPA-PPA single-mode coupon tests. The nominal traction stress consists of two components, namely: $t_{n}$ in the normal direction and $t_{s}$ in the shear direction, and these allow the simulation of damage initiation along the bond-line. The $G_{n}$ and $G_{s}$ values represent the areas under the traction separation law graphs in the normal and shear directions, respectively [38].

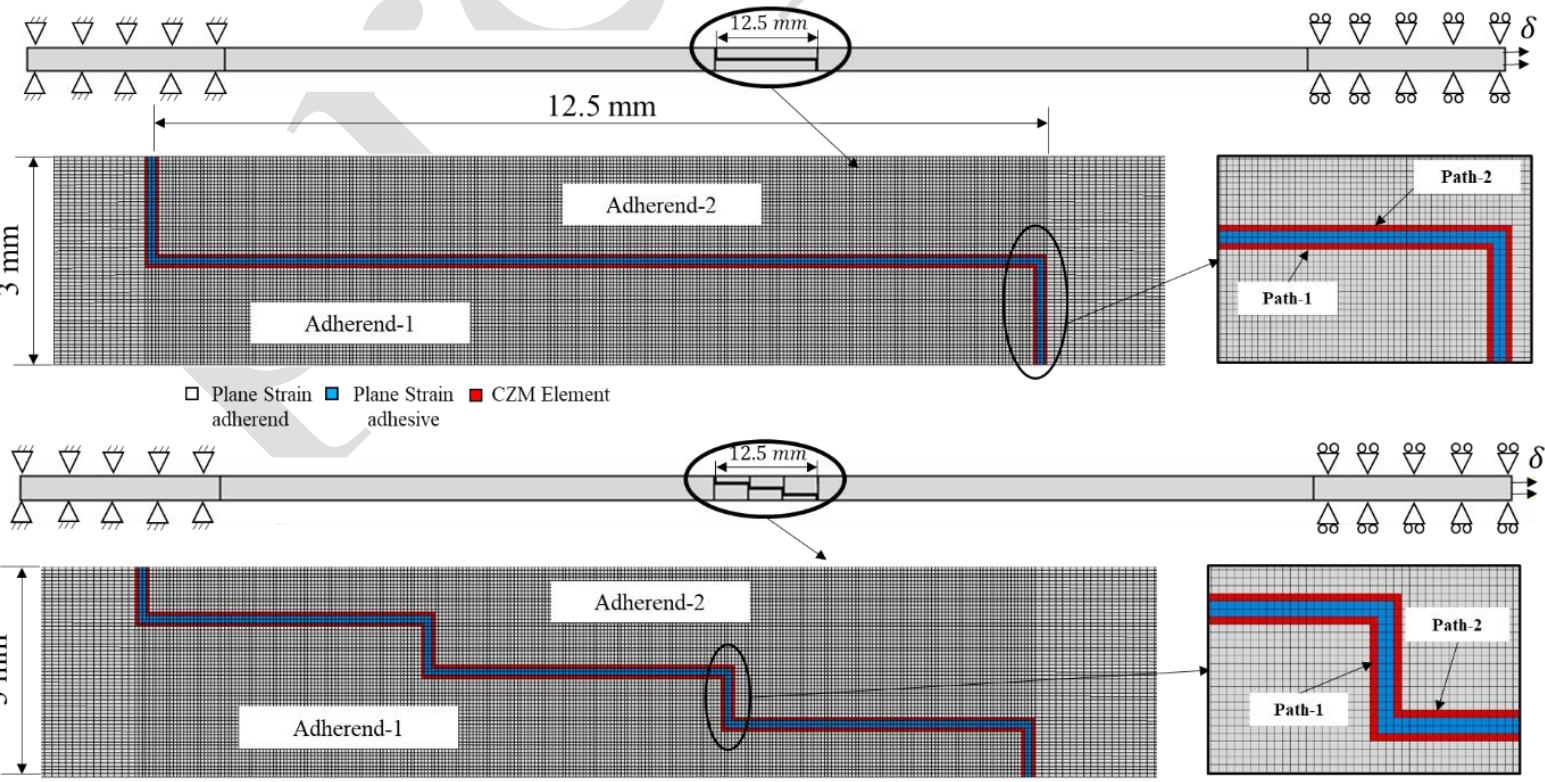

Figure 3: The boundary conditions and mesh details for the FE model of (a) the half-splice joint and (b) the stepped-lap joint with $L_{0}=12.5$ in Case 1 . 
In Case 2, a higher mesh refinement was used for the stress distribution analysis along the bond-line. The adherend and adhesive were meshed with elements of size $0.02 \mathrm{~mm} \times 0.02 \mathrm{~mm}$ in the bonding area, and a single bias was used for other parts of the adherend, with a maximum element size of $0.2 \mathrm{~mm}$ and a minimum element size of $0.02 \mathrm{~mm}$. Here, both the adhesive and the adherend sections were meshed using plane strain elements (CPE4R).

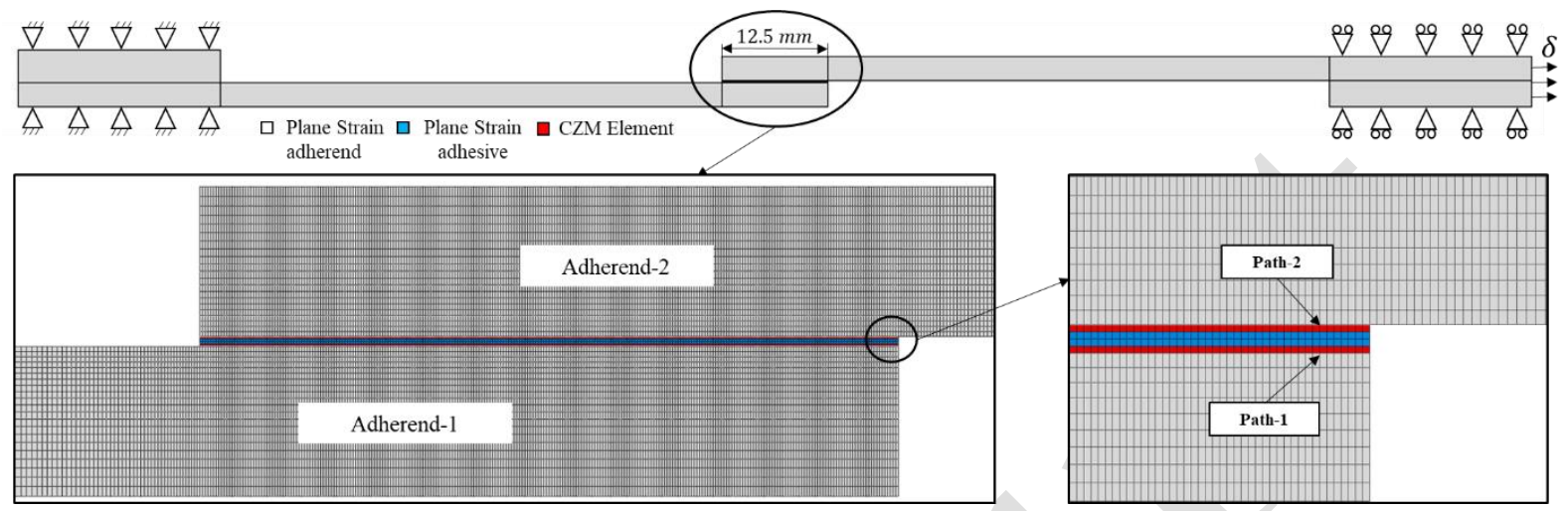

Figure 4: The boundary conditions and mesh details for the FE model of the single-lap joint with $L_{0}=12.5 \mathrm{~mm}$ in Case 1 .

For both Case 1 and Case 2, the models were fixed at the left end (Adherend 1), and a tensile displacement was applied at the right end (Adherend 2). Figure 4 and 5 show the boundary conditions for a single-lap joint and a scarf joint, respectively.

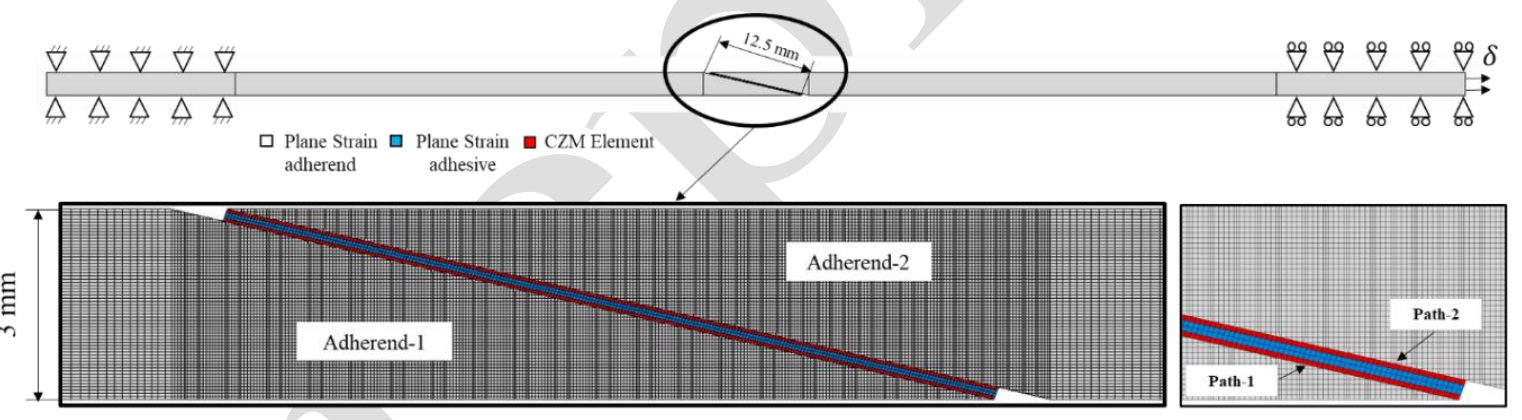

Figure 5: The boundary conditions and mesh details for the FE model of the scarf joint in Case 1.

\section{Results and Discussion:}

\subsection{Stress Distribution of Dissimilar Joints}

This section presents a comparison of the peel and shear stress distributions through the middle of the adhesive layer of the four different dissimilar joint configurations, for the overlap lengths $L_{0}$ $=12.5 \mathrm{~mm}$ and $L_{0}=50 \mathrm{~mm}$ (Figure 6 and 7). Of the four overlap lengths used during testing, these two magnitudes were selected as the representative values for the discussion of the stress distribution. For the scarf joints, the stress distributions were obtained at $\alpha=13.5^{\circ}$ and $\alpha=3.44^{\circ}$, meaning the corresponding overlap lengths were also approximately $12.5 \mathrm{~mm}$ and $50 \mathrm{~mm}$, respectively. All plots illustrate the stress under elastic deformation, normalised by the average shear stress $\left(\tau_{\text {avg }}\right)$ along the bond-line of each design (as shown in Figure 6 and 7). The position along the bond-line ( $x$ ) has also been normalised using the overall overlap length $\left(L_{0}\right)$. Based on the trend of the distribution, the overlap 
length has been divided into three sections: $0<\mathrm{x}<0.2$ (Section I, on the left), $0.2<\mathrm{x}<0.8$ (Section II, the overlapping inner region), and $0.8<\mathrm{x}<1$ (Section III, on the right).
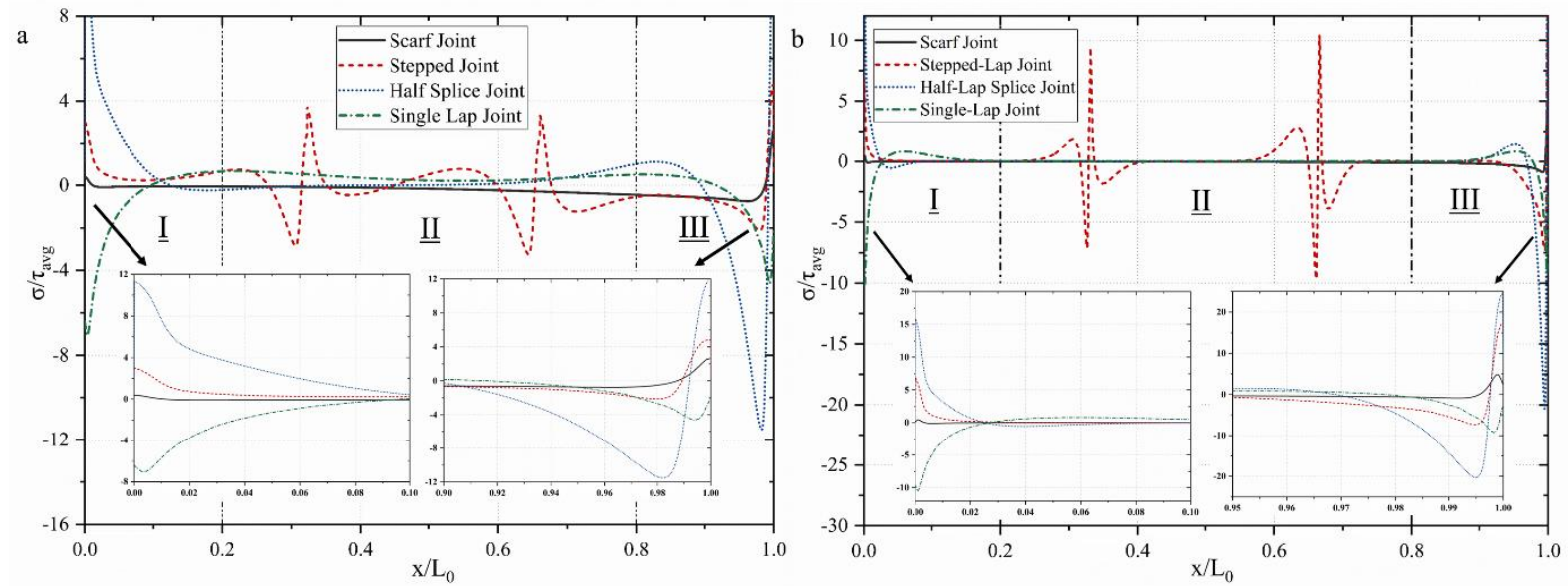

Figure 6: A comparison of $\sigma / \tau_{\mathrm{avg}}$ for the four dissimilar adhesively bonded joint types with two different overlap lengths:

(a) $12.5 \mathrm{~mm}$ and (b) $50 \mathrm{~mm}$.

For $L_{0}=12.5 \mathrm{~mm}$, the peak normalised peel stress value $\left(\sigma / \tau_{\mathrm{avg}}\right)$ in Section I (AL side), was 0.31 for the scarf joint, 3.02 for the stepped-lap joint, 11.32 for the half-lap splice joint and -7.07 for the singlelap joint (Figure 6a). In comparison, the $\sigma / \tau_{\text {avg }}$ values for the former three joints in Section III (PPA side), were higher by $87.5 \%, 37.47 \%$ and $8.26 \%$, respectively. This was a result of the difference in stiffness of the adherends, which resulted in an asymmetric peel stress distribution. Despite the fact that the scarf joint experienced the largest percentage difference in peak $\sigma / \tau_{\mathrm{avg}}$, it still had the lowest absolute peak $\sigma / \tau_{\text {avg }}$ value in Section III, measured at 2.48. The other joints reached 4.83 (stepped-lap joint), 12.34 (half-lap splice joint) and -4.64 (single-lap joint). Here, the stepped-lap joint had a lower peak $\sigma / \tau_{\text {avg }}$ value when compared to the single-lap joint and the half-lap splice joint, due to its stepwise design allowing a more even spread of the load between each step.

As the overlap length increased (from $L_{0}=12.5 \mathrm{~mm}$ to $L_{0}=50 \mathrm{~mm}$ ), higher $\sigma / \tau_{\text {avg }}$ values were developed in Sections I and III (i.e. the ends of the bond-line) because of a greater transmitted load and bending moment, as shown in Figure 6. In addition, the peak stresses obtained at both ends of the scarf joint were lower than those at the ends of the single-lap joint (

Table 5). This was due to the improved alignment of the adhesive layer with the applied load [4], which reduced the bending moment. The stepped-lap joint experienced the most significant increase in peak $\sigma / \tau_{\mathrm{avg}}$ at the ends of the bond-line, specifically from 3.02 to 6.77 in Section I (AL side) and 4.83 to 17.20 in Section III (PPA side), corresponding to $124.17 \%$ and $256.10 \%$ increases, respectively. The same trend was followed by the half-lap splice joint, only with slightly lower increases $(50.61 \%$ and $114.32 \%$ for Sections I and III, respectively). This suggests that the strength of stepped-lap joint and half-lap splice joint cannot be improved significantly by increasing $L_{0}$. 
Table 5: The absolute peak $\sigma / \tau_{\text {avg }}$ at the ends of the bond-line for the four types of dissimilar joints.

\begin{tabular}{lcccccccc}
\hline Overlap Length & \multicolumn{2}{c}{$\mathbf{1 2 . 5} \mathbf{~ m m}$} & \multicolumn{2}{c}{$\mathbf{2 5} \mathbf{~ m m}$} & \multicolumn{2}{c}{$\mathbf{3 7 . 5} \mathbf{~ m m}$} & \multicolumn{5}{c}{$\mathbf{5 0} \mathbf{~ m m}$} \\
\hline Section & I & III & I & III & I & III & I & III \\
\hline Scarf Joint & 0.31 & 2.48 & 0.33 & 3.28 & 0.38 & 4.13 & 0.44 & 4.64 \\
\hline Stepped-Lap Joint & 3.02 & 4.83 & 4.60 & 9.06 & 6.03 & 13.59 & 6.77 & 17.20 \\
\hline Half-Lap Splice Joint & 11.32 & 12.34 & 15.68 & 19.36 & 16.98 & 23.54 & 17.05 & 26.49 \\
\hline Single-Lap Joint & 7.07 & 4.64 & 10.81 & 7.75 & 11.22 & 8.93 & 11.42 & 9.29 \\
\hline
\end{tabular}

As shown in Figure 7a, the shear stresses for all joints were significantly concentrated in Section III, on account of the higher longitudinal straining of PPA in comparison to AL, due to its lower stiffness [39][40]. Of all the designs, the scarf joint had the lowest stress levels at both ends of the bond-line, with peak $\tau / \tau_{\text {avg }}$ values of 0.52 and 2.95 in Sections I and III, respectively. The uniform shear stress distribution was due to the tapering of the scarf joint edges, resulting in an almost cancelling effect on the shear lag [3]. Conversely, the peak $\tau / \tau_{\text {avg }}$ value is significantly higher in the other three joints, with the half-lap splice joint reaching a maximum of -3.73 in Section I and 12.1 in Section III (the two greatest magnitudes of $\tau / \tau_{\text {avg }}$ across the board). This higher peak $\tau / \tau_{\text {avg }}$ value at the PPA side (Section III) can be justified by the gradual decrease in the local stiffness along the bond-line, which increases the longitudinal deformation of the joint.
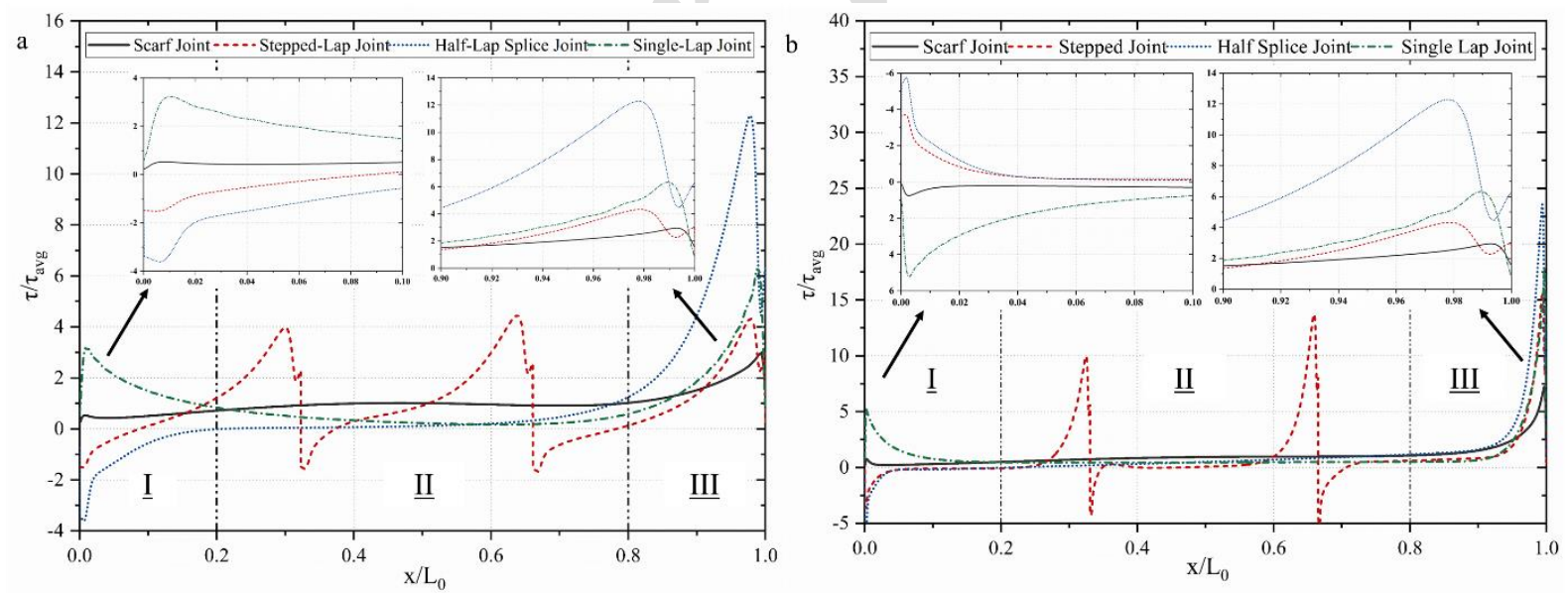

Figure 7: A comparison of $\tau / \tau_{\text {avg }}$ for the four dissimilar adhesively bonded joints with two different overlap lengths: (a) $12.5 \mathrm{~mm}$ and (b) $50 \mathrm{~mm}$.

When comparing the effects of overlap length, as depicted in Figure $7 \mathrm{a}$ and $7 \mathrm{~b}$, the change in peak $\tau / \tau_{\text {avg }}$ of the scarf joint in Section I is rather insignificant (from 0.54 at $L_{0}=12.5 \mathrm{~mm}$ to 0.72 at $L_{0}=$ $50 \mathrm{~mm}$ ). However, a bigger difference is obtained at the PPA side (from 2.88 at $L_{0}=12.5 \mathrm{~mm}$ to 7.2 at $L_{0}=50 \mathrm{~mm}$ ). The stepped-lap joint experienced a higher increase in its peak $\tau / \tau_{\text {avg }}$ value at the ends of the overlap length (PPA side) when compared to the single-lap and half-lap splice joints, with the $\tau / \tau_{\text {avg }}$ value peaking at 15.40 at $L_{0}=50 \mathrm{~mm}$, corresponding to a $256.10 \%$ increase. This can be justified by the increased axial deformation within each step of the adherend for larger $L_{0}$ values [41]. 
In the mid-section of the bond-line (Section II), the single-lap joint benefitted from an increased overlap length, which resulted in the cancellation of the asymmetric stress distribution caused by the dissimilar adherends. On the other hand, larger overlap lengths increased the peak $\tau / \tau_{\text {avg }}$ values at both edges of the single-lap joint, particularly at the PPA side (Section III), where a maximum of 17.86 was reached for the joint with $\mathrm{L}_{0}=50 \mathrm{~mm}$, in comparison to 6.1 for the joint with $\mathrm{L}_{0}=12.5 \mathrm{~mm}$. At the AL side (Section I), the $\tau / \tau_{\text {avg }}$ value had a maximum of 5.09 for the joint with $\mathrm{L}_{0}=50 \mathrm{~mm}$, in comparison to just 3.2 for the joint with $\mathrm{L}_{0}=12.5 \mathrm{~mm}$. In both cases, this can be justified by the increased longitudinal straining of each adherend along the bond-line, as a result of a higher transmitted load for the larger overlap length. The half-lap splice joint followed the same trend, but with a considerably smaller improvement in the concentration of $\tau / \tau_{\text {avg }}$ in Section II. Here, the peak $\tau / \tau_{\text {avg }}$ values at the ends of the bond-line (i.e. in Section I and III) were -3.73 for $\mathrm{L}_{0}=12.5 \mathrm{~mm}$ and -5.92 for $\mathrm{L}_{0}=50 \mathrm{~mm}$ in Section I (AL side), and 11.91 for $\mathrm{L}_{0}=12.5 \mathrm{~mm}$ and 22.92 for $\mathrm{L}_{0}=50 \mathrm{~mm}$ in Section III (PPA side).

Table 6: The absolute peak $\tau / \tau_{\text {avg }}$ at the ends of the bond-line for the four types of dissimilar joints.

\begin{tabular}{lcccccccc}
\hline Overlap Length & \multicolumn{2}{c}{$\mathbf{1 2 . 5} \mathbf{~ m m}$} & \multicolumn{2}{c}{$\mathbf{2 5} \mathbf{~ m m}$} & \multicolumn{2}{c}{$\mathbf{3 7 . 5} \mathbf{~ m m}$} & \multicolumn{2}{c}{$\mathbf{5 0} \mathbf{~ m m}$} \\
\hline Section & I & III & I & III & I & III & I & III \\
\hline Scarf Joint & 0.51 & 2.92 & 0.53 & 4.71 & 0.61 & 6.01 & 0.72 & 6.92 \\
\hline Stepped-Lap Joint & 1.52 & 4.32 & 2.47 & 8.32 & 3.20 & 11.86 & 3.73 & 15.40 \\
\hline Half-lap Splice Joint & 3.54 & 12.33 & 5.47 & 19.64 & 5.72 & 23.2 & 6.05 & 23.32 \\
\hline Single-Lap Joint & 3.71 & 6.32 & 4.93 & 11.22 & 5.10 & 15.04 & 5.51 & 17.60 \\
\hline
\end{tabular}

Table 6 shows the absolute peak $\tau / \tau_{\text {avg }}$ values for the four different configurations of dissimilar joints at the ends of the bond-line (Section I and III) with various overlap lengths. As the overlap length is increased, these values change only slightly in Section I (AL side), while every joint type experiences a significant increase in their peak $\tau / \tau_{\text {avg }}$ values in Section III (PPA side). The reasoning for this is the difference in bending and longitudinal deformation at the AL side (Section I) compared to the PPA side (Section III). In Section III, the largest increase in peak $\tau / \tau_{\text {avg }}$ occurs when the overlap length was increased from $\mathrm{L}_{0}=12.5 \mathrm{~mm}$ to $\mathrm{L}_{0}=25 \mathrm{~mm}$, and the percentage increases of the peak $\tau / \tau_{\text {avg }}$ values are $63 \%, 96 \%, 58 \%$ and $77 \%$ for the scarf joint, stepped-lap joint, half-lap splice joint and single-lap joint, respectively. Contrastingly, the peak $\tau / \tau_{\text {avg }}$ value for all joints rose by less than $40 \%$ when the overlap length was increased from $\mathrm{L}_{0}=37.5 \mathrm{~mm}$ to $\mathrm{L}_{0}=50 \mathrm{~mm}$.

\subsection{Joint Strength Analysis}

This section presents the analysis of the experimental failure loads $\left(\mathrm{P}_{\mathrm{m}}\right)$ for all four adhesively bonded joints. In Figure 8, the $\mathrm{P}_{\mathrm{m}}$ for all combinations of adherends (AL-AL, AL-PPA and PPA-PPA) are depicted. It is clear that the failure load of all joints increases as the overlap length $\left(\mathrm{L}_{0}\right)$ increases. 
Among the joints with identical adherends (AL-AL and PPA-PPA), the scarf joint outperforms all other joints, since the higher $L_{0}$ in the scarf joint can be achieved with a smaller scarf angle $(\alpha)$ which cancels the peak stress effect and leads to a higher $\mathrm{P}_{\mathrm{m}}$ [21].

For the AL-AL joints (Figure 8a), the failure load of the stepped-lap configuration was only $13 \%$ lower than that of the scarf configuration with $\mathrm{L}_{0}=12.5 \mathrm{~mm}$, due to the lower peak stresses at the edges of the stepped-lap joint. However, the $P_{m}$ of the scarf joint experienced a $102 \%$ growth as the overlap length was increased from $12.5 \mathrm{~mm}$ to $50 \mathrm{~mm}$, while this increase is only $24 \%$ for the stepped-lap joint. The same tendency was observed for the PPA-PPA joints (Figure 8b).

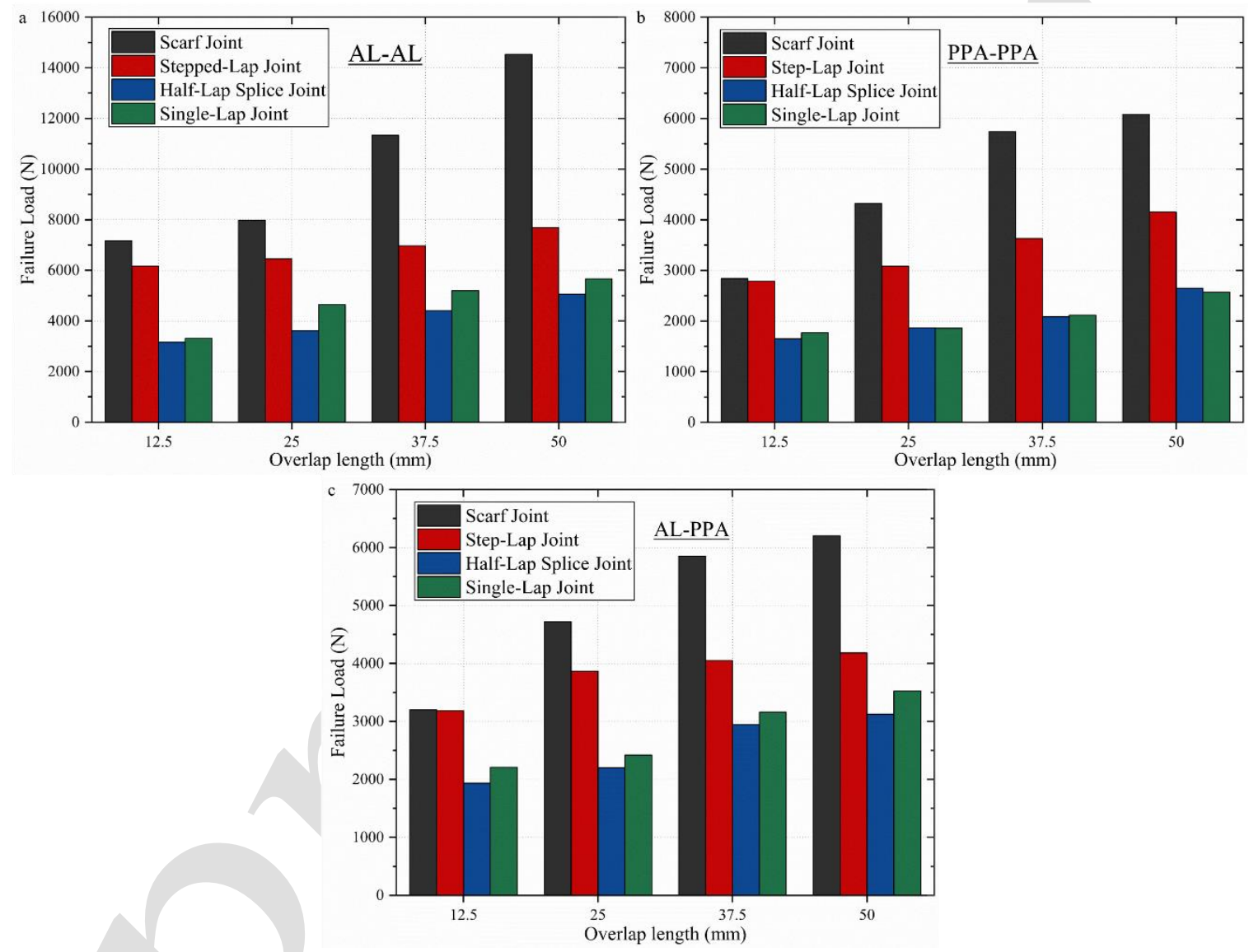

Figure 8: The failure loads of four different adhesively bonded joints with three combinations of adherends: (a) AL-AL, (b) PPA-PPA, and (c) AL-PPA.

For the AL-PPA joints (Figure 8c), the $P_{m}$ values for the scarf and stepped-lap joints were similar to each other when the overlap length $\mathrm{L}_{0}$ is $25 \mathrm{~mm}$, due to the lower peak stresses at the edges of the stepped-lap joints. As the overlap length was increased from $12.5 \mathrm{~mm}$ to $25 \mathrm{~mm}$, the $P_{m}$ values increase by $47.50 \%$ and $21.25 \%$ for the scarf and the stepped-lap joints, respectively. When the overlap length was increased to $\mathrm{L}_{0}=37.5 \mathrm{~mm}$, the $P_{m}$ values increased noticeably by $23 \%$ for the scarf joint and only by $5 \%$ for the stepped-lap joint. This can be justified by the stress analysis results as the higher peak stresses are obtained for higher values of $\mathrm{L}_{0}$. The marginally better performance of the scarf joint could be accounted for by its smaller bending moment. 


\subsection{Failure Load Analysis}

This section is a numerical and experimental study into the effects of adherend stiffness on the different configurations of adhesive joints with various overlap lengths. Figure 9 shows the average failure load $\left(P_{m}\right)$ for all configurations and adherend combinations at four $\mathrm{L}_{0}$ values, each obtained from four experimental tests. The estimated numerical failure loads $\left(P_{0}\right)$ are also shown, and these were obtained using the cohesive zone model (CZM).

As seen in Figure 9, increasing adherend stiffness increases the maximum failure load for all four joint configurations. The highest failure load was achieved with AL-AL joints (rather than PPA-PPA or ALPPA joints), due to the decreased bending and lessened longitudinal deformation in the AL-AL joint, leading to a more uniform stress distribution along the bond-line. The $P_{m}$ values for the AL-PPA and PPA-PPA joints are noticeably similar, with the dissimilar AL-PPA joints performing only slightly better when the two types are compared. This is due to the presence of the higher-stiffness adherend (AL) in the AL-PPA joints, which leads to reduced bending, providing a smaller shear stress concentration at the AL side (shown in Figure 7). Although the AL-PPA joints outperform the PPAPPA joints, they cannot reach the success of the AL-AL joints. This is due to the asymmetric stress distribution in the dissimilar joints (AL-PPA), which leads to a significantly higher stress concentration in the interface between the lower-stiffness adherend (PPA) and the adhesive.

For the largest overlap length $\left(L_{0}=50 \mathrm{~mm}\right)$, the load-carrying capacity of the AL-AL joints increased significantly for all four configurations. However, the AL-PPA and PPA-PPA joints did not follow the same tendency - for these adherend combinations, considerably smaller $P_{m}$ improvements were recorded with increasing $L_{0}$. This poor performance can be explained by higher peel and shear stress concentrations at the overlap length edge, caused by the lower-stiffness adherend (PPA). By changing the adherend combination from AL-AL to AL-PPA at $L_{0}=50 \mathrm{~mm}$, the $P_{m}$ value decreased by $55 \%$ for the scarf joint, $40 \%$ for the stepped-lap joint, $37 \%$ for the half-lap splice joint and $36 \%$ for the singlelap joint, respectively. Here, the reduction percentage is higher for the scarf and stepped-lap joints as the PPA failed due to the higher tensile loads reached, meaning the joints could not perform to their full capacity (Figure 11-12). 

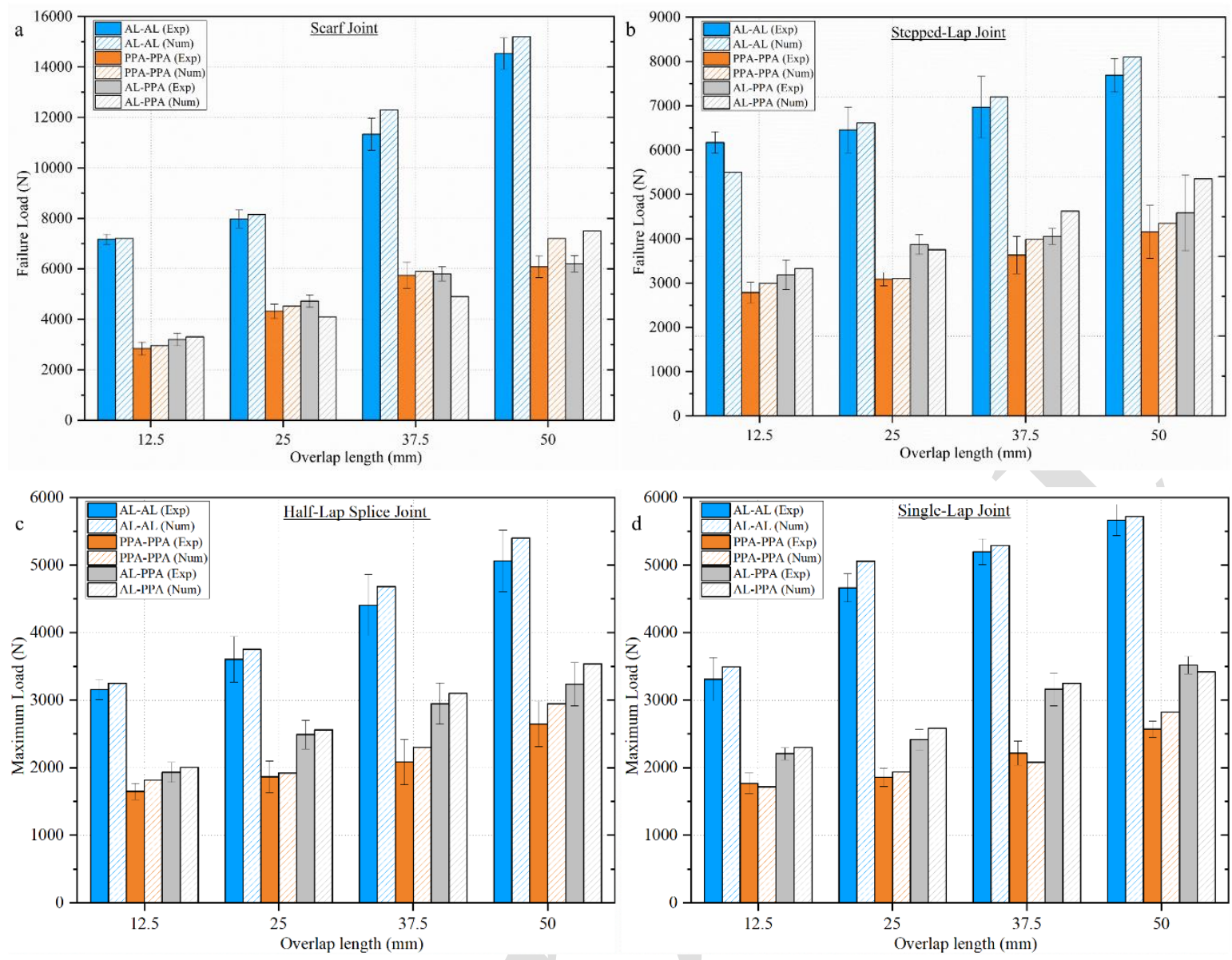

Figure 9: An experimental and numerical comparison of the $P_{m}$ values for (a) scarf joints, (b) stepped-lap joints, (c) half-lap splice joints and (d) single-lap joints with various overlap lengths.

There is good agreement between the experimental and numerical failure loads for all adhesive joint configurations. As seen in Figure 9, the difference between the $P_{m}$ and $P_{0}$ values for each $L_{0}$ is notably small (around 5\%) up to $L_{0}=25 \mathrm{~mm}$, while the differences gradually rise to $20 \%$ as $L_{0}$ increases further. The larger differences here are due to the greater transmitted load and therefore higher stress concentrations at the joint edges for larger $L_{0}$, causing either plasticisation or total failure of the adherend in the experiment, which the failure criteria or plastic behaviour in the numerical simulations did not account for. The failure criteria were only used for the epoxy adhesive and not the adherends. For the scarf and stepped-lap joints specifically, at $L_{0}=50 \mathrm{~mm}$, the failure spread to the PPA adherend as opposed to occurring solely within the epoxy adhesive (Figure 10 and Error! Reference source not found.). This can be explained by the greater load-carrying capacity of the scarf and stepped-lap joints resulting in a higher stress concentration along the bond-line of the adherend section, causing the adherend to fail. 


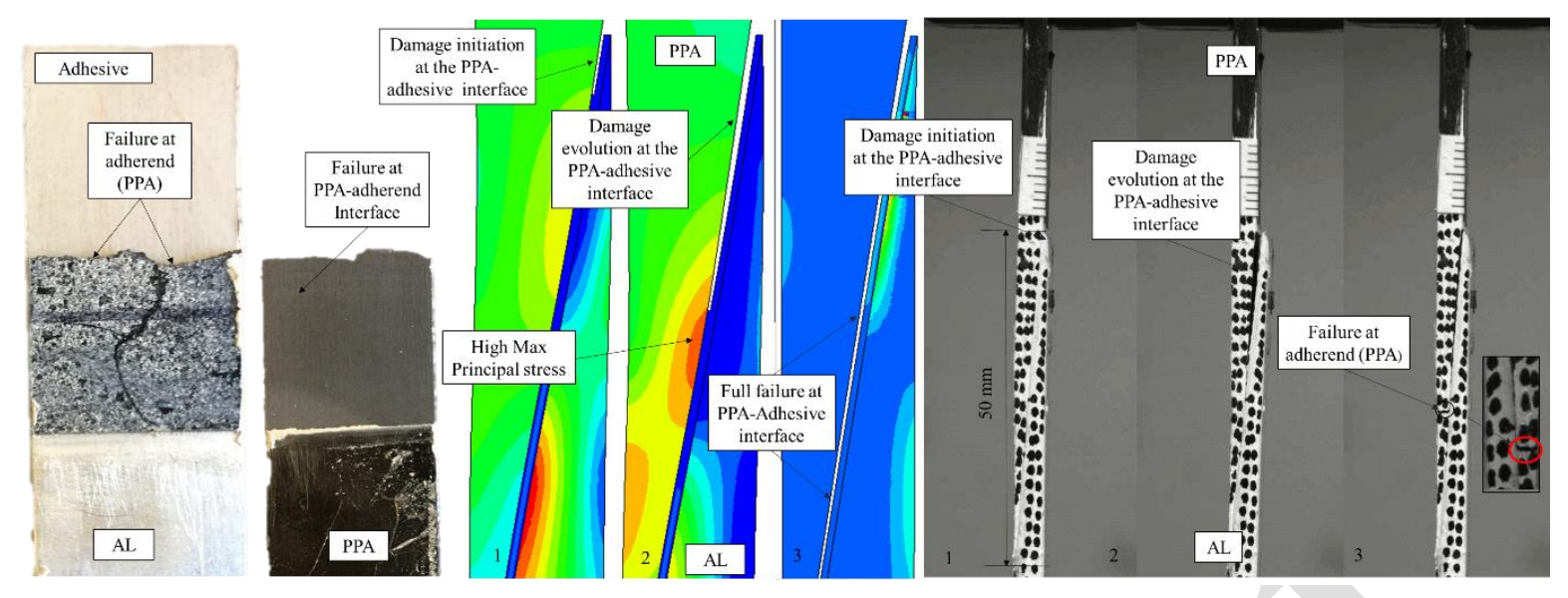

Figure 10: The failure process of a dissimilar scarf joint at $L_{0}=50 \mathrm{~mm}$.

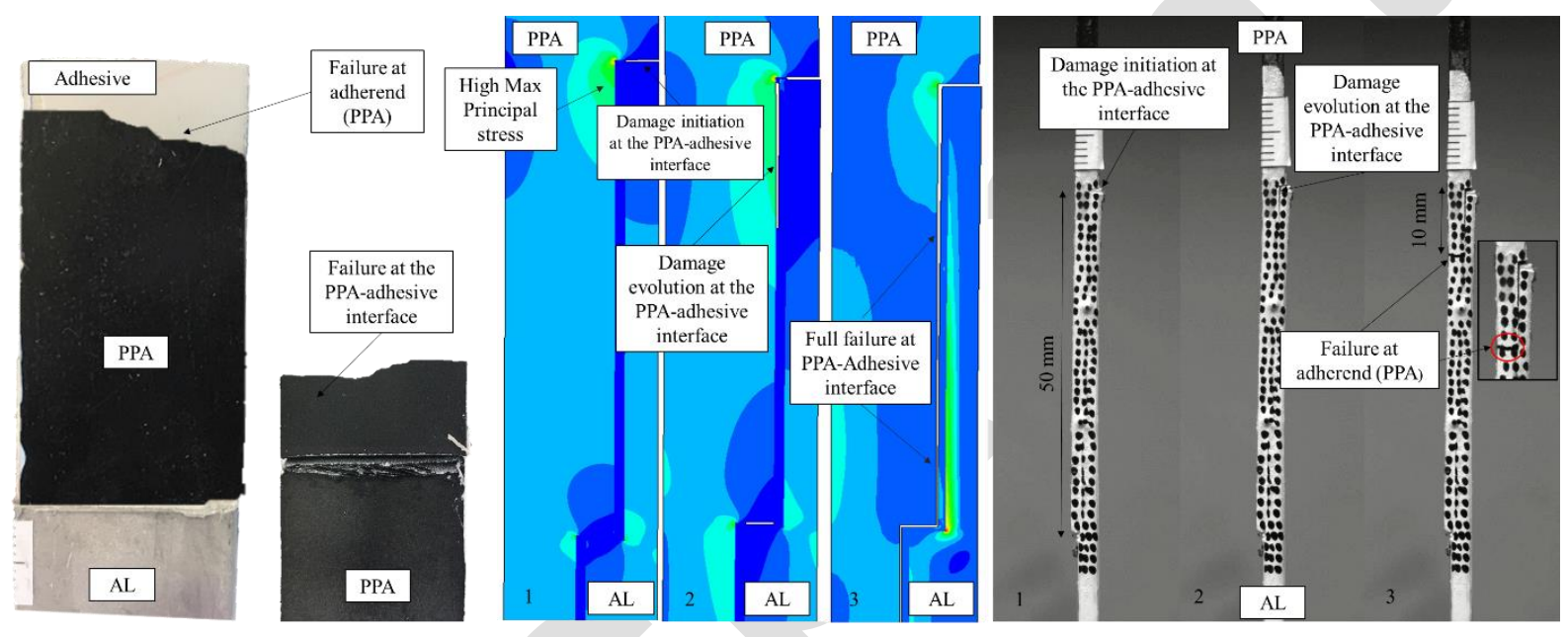

Figure 11: The failure process of a dissimilar stepped-lap joint at $L_{0}=50 \mathrm{~mm}$.

\subsection{Damage Variable of Dissimilar Joints}

In this section, the focus lies on the stiffness degradation (SDEG variable in Abaqus) of the CZM elements across the different overlap lengths $\left(0 \leq x / L_{0} \leq 1\right)$. As in Section 4.1, of the four overlap lengths used, $L_{0}=12.5 \mathrm{~mm}$ and $L_{0}=50 \mathrm{~mm}$ were selected as the representative overlap lengths for the discussion here. The SDEG value varies between 0 (undamaged) and 1 (fully damaged).

For all four dissimilar joint configurations (Figure 12), the numerical and experimental results show that the failure is always initiated at the PPA-adhesive interface, and the stiffness difference between the two adherends causes the SDEG to behave asymmetrically, leading to a higher stress concentration along the bond-line edge of Adherend 2 (Section III in Figure 6 and 7). It can therefore be concluded that the adherend with the lower stiffness affects the strength of the whole joint significantly. 
a)

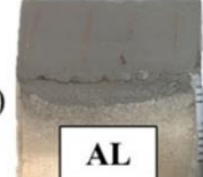

b)

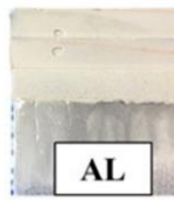

c)

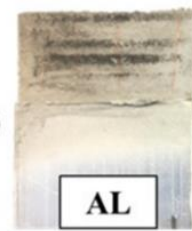

d)
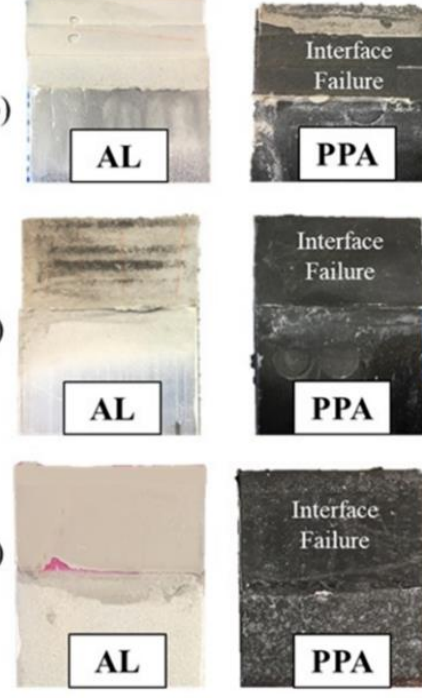

Failure

PPA
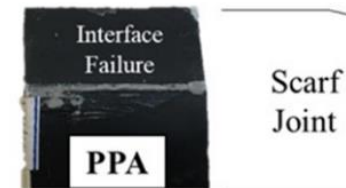

Joint
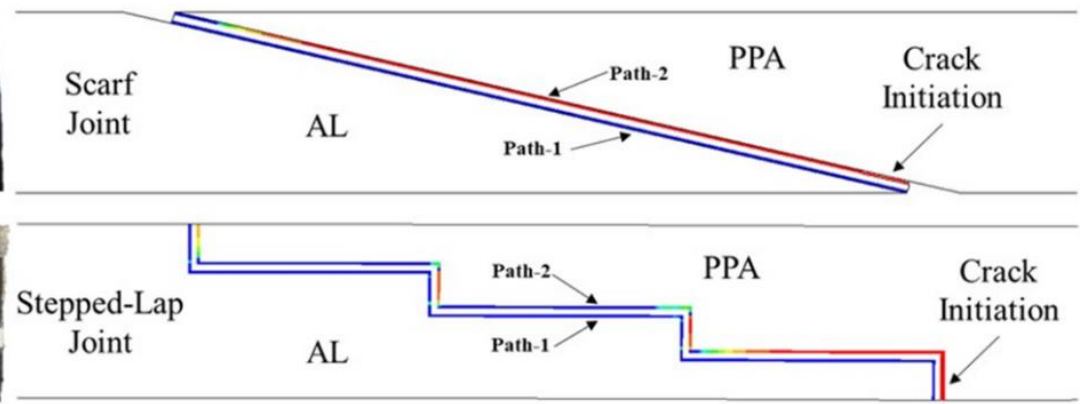

AL
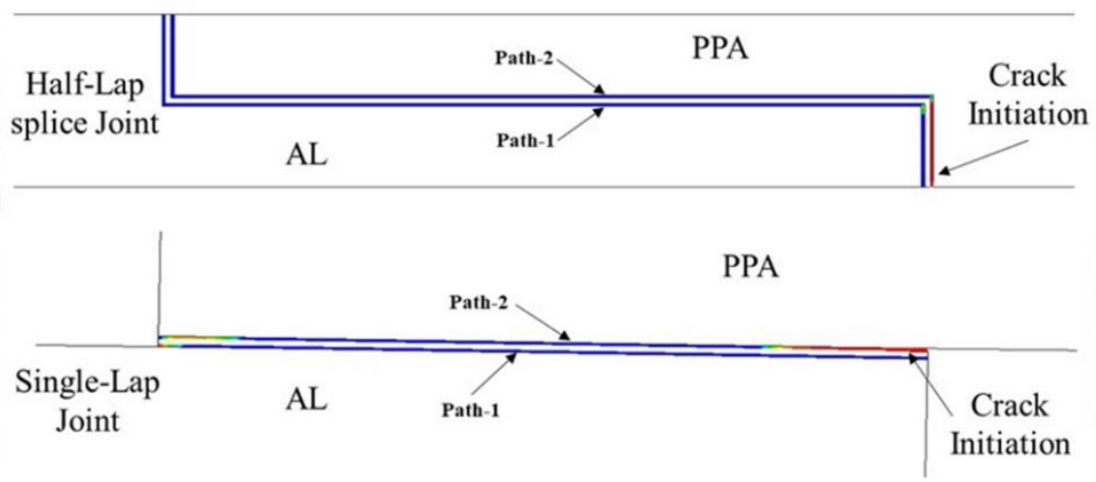

Figure 12: The failure process in (a) scarf joints, (b) stepped-lap joints, (c) half-lap splice joints and (d) single-lap joints for $L_{0}=12.5 \mathrm{~mm}$.

Analysis for the SDEG was conducted for Path 2 (PPA side) at the maximum failure load. As shown in Figure 13a, the scarf joint was able to spread damage most evenly, followed by the single-lap joint, with $91 \%$ and $77 \%$ of their overlap lengths under damage, respectively. The scarf joint's success was due to the influence of the tapered adherend near the scarfed tip, decreasing the bending caused by the dissimilar adherends [3]. On the other hand, the total amount of overlap length under damage is considerably lower for the stepped-lap (55\%) and half-lap splice (33\%) joints. This is because of the stepwise construction of these joints resulting in a higher intensity of damage at the bond-line edges, due to the greater stress concentration in these areas. Moreover, the stepped-lap joint performs slightly better than the half-lap splice joint, as it spreads damage between steps with a higher preponderance in the outer ones.

For larger overlap lengths (Figure 13b), the damage is less spread-out due to the increase in the magnitude of the shear stress in Section III (PPA side), adversely affecting the epoxy adhesive which is sensitive to peak stresses at the edges of the bond-line. In other words, the epoxy adhesive fails immediately after reaching the stress softening phase in the damage law [42] after tolerating limited damage. Despite the fact that increasing the overlap length reduces the total length under damage for all dissimilar joints, the stepped-lap joint experienced a less noticeable drop compared to the other joints. The reduction for the stepped-lap joint was 39\%, in comparison to $69 \%$ and $63 \%$ for the scarf joint and the single-lap joint, respectively. This is because the stepped-lap joint spreads load more evenly between its steps due to the $t_{p}$ reduction effect [41]. However, the scarf joint still has the best 
performance here with $28 \%$ of its overlap length under damage compared to only $26 \%, 23 \%$ and $5 \%$ for the single-lap, stepped-lap and half-lap splice joints, respectively.
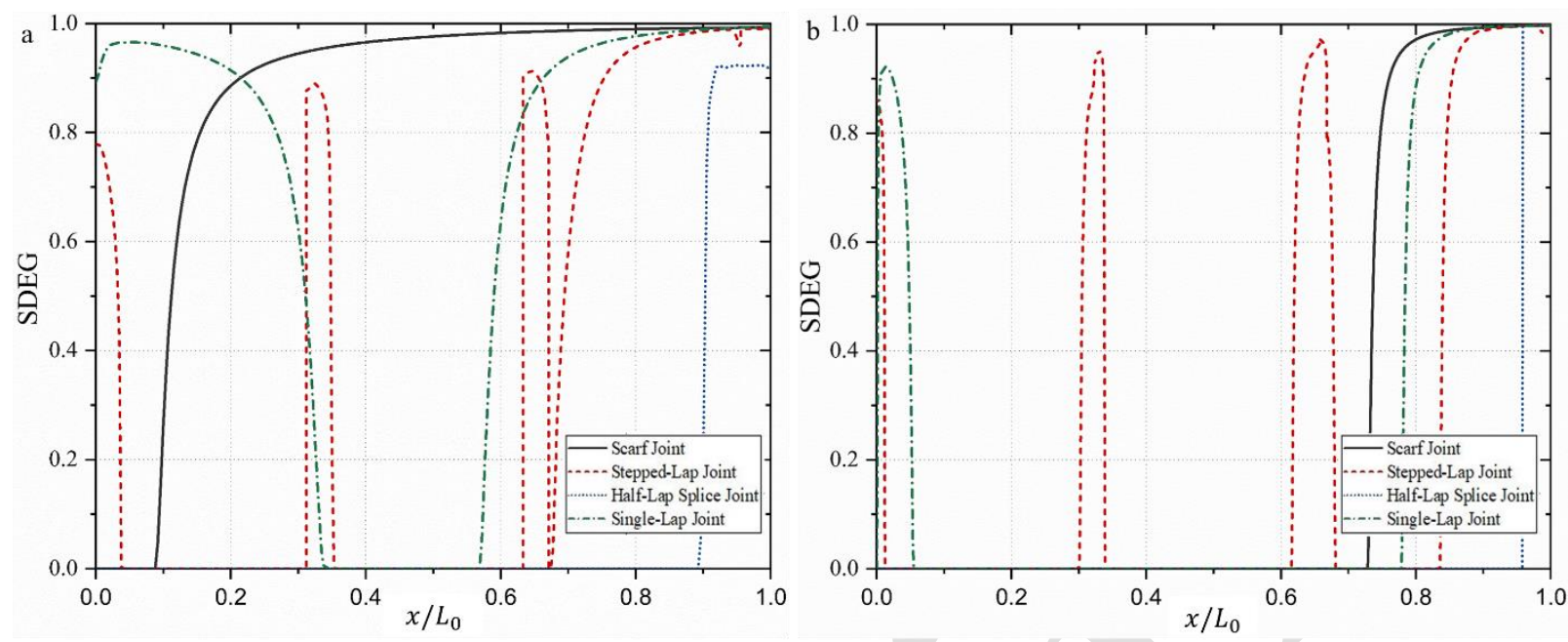

Figure 13: The damage variable (SDEG) of the dissimilar joints in Path 2 (PPA side), under the maximum load points at (a) $\mathrm{L}_{0}=12.5 \mathrm{~mm}$ and (b) $\mathrm{L}_{0}=50 \mathrm{~mm}$

\section{Conclusion}

In this work, a comparative study involving four joint configurations (scarf joints, stepped-lap joints, half-lap splice joints and single-lap joints) and three different adherend combinations was carried out, with the aim of determining the most suitable dissimilar bonded joint design. In addition, the effects of the overlap length $\left(L_{0}\right)$ and the mechanical properties of the adherends on the overall performances of the joints were also explored. The conclusions are summarised as follows:

- The scarf joint provides the best performance, followed by the stepped-lap joint, both with lower peak $\tau_{\mathrm{xy}} / \tau_{\mathrm{avg}}$ and $\sigma_{\mathrm{y}} / \tau_{\mathrm{avg}}$ values than the other joints. Scarf joints spread damage more evenly due to the tapering of the adherend near the scarfed tip. This leads to lower stress along the bond-line and decreased bending, counteracting the influence of the dissimilar adherends. The lower stress concentrations in the stepped-lap joint can be justified by the fact that the stepped-lap joint divides the load much more efficiently due to its stepwise nature.

- By increasing the overlap length $\left(L_{0}\right)$, the peak stresses at the ends of the bond-line also increase for all joints, due to a higher transmitted load and bending moment. However, smaller peak stresses are obtained for the scarf joint at both ends of the bond-line in comparison to the other three joints, irrespective of $L_{0}$. The stepped-lap and half-lap splice joints experienced the most significant increase in peak stresses at the edges of the bond-line. This suggests that increasing the overlap length could increase the strength of the dissimilar scarf joint, but this would not be the case for the stepped-lap and half-lap splice joints.

- For all four joint configurations, the load-carrying capacity of the AL-AL joints increased significantly as the overlap length $\left(L_{0}\right)$ got larger. However, the AL-PPA and PPA-PPA joints 
did not follow the same tendency - for these adherend combinations, considerably smaller $\mathrm{P}_{\mathrm{m}}$ improvements were recorded with increasing $\mathrm{L}_{0}$. In joints with identical adherends (AL-AL and PPA-PPA), the scarf joint outperformed all other joints. On the other hand, for the AL-PPA joints, the $\mathrm{P}_{\mathrm{m}}$ values for the scarf joints and stepped-lap joints were notably close to one another for the overlap lengths up to $L_{0}=25 \mathrm{~mm}$. Despite the high performance of the stepped-lap joint for lower $\mathrm{L}_{0}$, the rate of increase in its performance quality is significantly lower than the scarf joint for higher $\mathrm{L}_{0}$ values, as the stress concentration rises considerably at the PPA side, which results in the failure of the PPA or the adhesive.

- The numerical and experimental failure analysis shows that the failure is always initiated at the PPA-adhesive interface in multi-material joints (AL-PPA), regardless of the joint configuration. The asymmetric behaviour of SDEG is due to the stiffness difference between the two adherends, leading to a higher stress concentration at the edge of the bond-line adjacent to the lower stiffness adherend, and it can therefore be concluded that the adherend with lowerstiffness affects the strength of the whole joint significantly. In addition, the SDEG plots demonstrate that the scarf joint was able to spread damage most evenly, followed by the singlelap joint, both of which had large proportions of the overlap length under damage. On the other hand, the total overlap length under damage is considerably lower for the stepped-lap and halflap splice joints. This is because of the stepwise construction of these joints, which results in a higher intensity of damage at the bond-line edges due to the greater stress concentrations in these areas.

\section{Conflict of interest}

There is no conflict of interest in this research work.

\section{Acknowledgements}

The authors wish to acknowledge the support of the Engineering Department of Lancaster University, UK. 


\section{References:}

[1] N. G. C. Barbosa, R. D. S. G. Campilho, F. J. G. Silva, and R. D. F. Moreira, "Comparison of different adhesivelybonded joint types for mechanical structures,” Appl. Adhes. Sci., vol. 6, no. 1, p. 15, Dec. 2018.

[2] S. Akpinar, "The strength of the adhesively bonded step-lap joints for different step numbers," Compos. Part B Eng., vol. 67, pp. 170-178, Dec. 2014.

[3] R. D. F. Moreira and R. D. S. G. Campilho, "Strength improvement of adhesively-bonded scarf repairs in aluminium structures with external reinforcements,” Eng. Struct., vol. 101, pp. 99-110, Oct. 2015.

[4] R. D. S. G. Campilho and T. A. B. Fernandes, "Comparative Evaluation of Single-lap Joints Bonded with Different Adhesives by Cohesive Zone Modelling,” Procedia Eng., vol. 114, pp. 102-109, Jan. 2015.

[5] S. Bayramoglu, K. Demir, and S. Akpinar, "Investigation of internal step and metal part reinforcement on joint strength in the adhesively bonded joint: Experimental and numerical analysis," Theor. Appl. Fract. Mech., vol. 108, no. March, p. 102613, Aug. 2020.

[6] J. Zhang, H.-Y. Li, H. Li, and H. Jia, "Investigation on fatigue performance of adhesively bonded butt-joints and multiaxial life estimation using stress-based failure models," Theor. Appl. Fract. Mech., vol. 107, no. January, p. 102498, Jun. 2020

[7] A. Kimiaeifar, E. Lund, O. T. Thomsen, and J. D. Sørensen, “Asymptotic Sampling for reliability analysis of adhesive bonded stepped lap composite joints,” Eng. Struct., vol. 49, pp. 655-663, Apr. 2013.

[8] A. J. Gunnion and I. Herszberg, "Parametric study of scarf joints in composite structures," Compos. Struct., vol. 75, no. 1-4, pp. 364-376, Sep. 2006.

[9] R. Bai, S. Bao, Z. Lei, C. Yan, and X. Han, "Finite element inversion method for interfacial stress analysis of composite single-lap adhesively bonded joint based on full-field deformation," Int. J. Adhes. Adhes., vol. 81, pp. 48-55, Mar. 2018.

[10] H. S. Kim, S. J. Lee, and D. G. Lee, "Development of a strength model for the cocured stepped lap joints under tensile loading," Compos. Struct., vol. 32, no. 1-4, pp. 593-600, Jan. 1995.

[11] P. N. B. Reis, J. A. M. Ferreira, and F. Antunes, "Effect of adherend's rigidity on the shear strength of single lap adhesive joints," Int. J. Adhes. Adhes., vol. 31, no. 4, pp. 193-201, Jun. 2011.

[12] T. Sawa, K. Ichikawa, Y. Shin, and T. Kobayashi, "A three-dimensional finite element stress analysis and strength prediction of stepped-lap adhesive joints of dissimilar adherends subjected to bending moments," Int. J. Adhes. Adhes., vol. 30, no. 5, pp. 298-305, Jul. 2010.

[13] K. Ichikawa, Y. Shin, and T. Sawa, "A three-dimensional finite-element stress analysis and strength evaluation of stepped-lap adhesive joints subjected to static tensile loadings," Int. J. Adhes. Adhes., vol. 28, no. 8, pp. 464-470, Dec. 2008.

[14] T. Sawa, J. Liu, K. Nakano, and J. Tanaka, "Two-dimensional stress analysis of single-lap adhesive joints of dissimilar adherends subjected to tensile loads," J. Adhes. Sci. Technol., vol. 14, no. 1, pp. 43-66, 2000.

[15] A. M. G. Pinto, A. G. Magalhães, R. D. S. G. Campilho, M. F. S. F. de Moura, and A. P. M. Baptista, "Single-lap joints of similar and dissimilar adherends bonded with an acrylic adhesive," J. Adhes., vol. 85, no. 6, pp. 351-376, 2009.

[16] S. Akpinar, "Effects of laminate carbon/epoxy composite patches on the strength of double-strap adhesive joints: Experimental and numerical analysis," Mater. Des., vol. 51, pp. 501-512, Oct. 2013.

[17] A. Ozel, B. Yazici, S. Akpinar, M. D. Aydin, and Ş. Temiz, "A study on the strength of adhesively bonded joints with different adherends,” Compos. Part B Eng., vol. 62, pp. 167-174, Jun. 2014.

[18] S. Akpinar, "The Effect of Composite Patches on the Failure of Adhesively-Bonded Joints Under Bending Moment," Appl. Compos. Mater., vol. 20, no. 6, pp. 1289-1304, Dec. 2013.

[19] U. A. Khashaba and I. M. R. Najjar, "Adhesive layer analysis for scarf bonded joint in CFRE composites modified with MWCNTs under tensile and fatigue loads," Compos. Struct., vol. 184, pp. 411-427, Jan. 2018.

[20] S. B. Kumar, I. Sridhar, S. Sivashanker, S. O. Osiyemi, and A. Bag, "Tensile failure of adhesively bonded CFRP composite scarf joints," Mater. Sci. Eng. B, vol. 132, no. 1-2, pp. 113-120, Jul. 2006.

[21] D. F. O. Silva, R. D. S. G. Campilho, F. J. G. Silva, and U. T. F. Carvalho, "Application a direct/cohesive zone method for the evaluation of scarf adhesive joints," Appl. Adhes. Sci., vol. 6, no. 1, p. 13, Dec. 2018. 
[22] I. U. Ojalvo and H. L. Eidinoff, "Bond Thickness Effects upon Stresses in Single-Lap Adhesive Joints," AIAA J., vol. 16, no. 3, pp. 204-211, Mar. 1978.

[23] Jiemin Liu and T. Sawa, "Stress analysis and strength evaluation of single-lap band adhesive joints subjected to external bending moments," J. Adhes. Sci. Technol., vol. 13, no. 6, pp. 729-749, 2008.

[24] M. Y. Tsai and J. Morton, “An evaluation of analytical and numerical solutions to the single-lap joint," Int. J. Solids Struct., vol. 31, no. 18, pp. 2537-2563, Sep. 1994.

[25] W. J. Renton and J. R. Vinson, "Analysis of Adhesively Bonded Joints Between Panels of Composite Materials,” J. Appl. Mech., vol. 44, no. 1, p. 101, 1977.

[26] K. Gültekin, S. Akpinar, and A. Özel, "The effect of the adherend width on the strength of adhesively bonded single-lap joint: Experimental and numerical analysis,” Compos. Part B Eng., vol. 60, pp. 736-745, Apr. 2014.

[27] O. Sayman, "Elasto-plastic stress analysis in an adhesively bonded single-lap joint," Compos. Part B Eng., vol. 43, no. 2, pp. 204-209, Mar. 2012.

[28] K. Gültekin, S. Akpinar, and A. Özel, "The Effect of Moment and Flexural Rigidity of Adherend on the Strength of Adhesively Bonded Single Lap Joints,” J. Adhes., vol. 91, no. 8, pp. 637-650, Aug. 2015.

[29] S. Akpinar and A. Ozel, "Experimental and numerical determination of the thermal cycle performance of joints obtained with nanostructure-doped nanocomposite adhesives," Compos. Part B Eng., vol. 174, no. May, p. 106959, Oct. 2019.

[30] Jiemin Liu, T. Sawa, and H. Toratani, "A two-dimensional stress analysis of single-lap adhesive joints subjected to external bending moments," J. Adhes. Sci. Technol., vol. 12, no. 8, pp. 795-812, 1998.

[31] J. Liu, T. Sawa, and H. Toratani, "A Two-dimensional Stress Analysis and Strength of Single-lap Adhesive Joints of Dissimilar Adherends Subjected to External Bending Moments," J. Adhes., vol. 69, no. 3-4, pp. 263-291, 2007.

[32] S. Akpinar, M. O. Doru, A. Özel, M. D. Aydin, and H. G. Jahanpasand, "The effect of the spew fillet on an adhesively bonded single-lap joint subjected to bending moment," Compos. Part B Eng., vol. 55, pp. 55-64, Dec. 2013.

[33] F. A. Stuparu, D. A. Apostol, D. M. Constantinescu, C. R. Picu, M. Sandu, and S. Sorohan, "Cohesive and XFEM evaluation of adhesive failure for dissimilar single-lap joints," Procedia Struct. Integr., vol. 2, pp. 316-325, 2016.

[34] K. MORI and T. SUGIBAYASHI, "Prediction of Strength of Stepped-Lap Bonded Joint with Adhesive Resin Under Tensile Shear Load,” JSME Int. journal. Ser. 1, Solid Mech. strength Mater., vol. 33, no. 3, pp. 349-355, 1990.

[35] K. MORI, H. ISONO, and T. SUGIBAYASHI, "Fracture Behavior and Strength of Stepped-Lap Bonded Joint with Adhesive Resin under Tensile Loading," JSME Int. journal. Ser. A, Mech. Mater. Eng., vol. 39, no. 3, pp. 398-406, Jul. 1996.

[36] T. Sawa, K. Ichikawa, Y. Shin, and T. Kobayashi, "A three-dimensional finite element stress analysis and strength prediction of stepped-lap adhesive joints of dissimilar adherends subjected to bending moments," Int. J. Adhes. Adhes., vol. 30, no. 5, pp. 298-305, Jul. 2010.

[37] A. Y. Kanani, Y. Liu, D. J. Hughes, J. Ye, and X. Hou, "Fracture mechanisms of hybrid adhesive bonded joints: Effects of the stiffness of constituents," Int. J. Adhes. Adhes., vol. 102, p. 102649, Oct. 2020.

[38] R. D. S. G. Campilho, M. D. Banea, J. A. B. P. Neto, and L. F. M. da Silva, "Modelling of Single-Lap Joints Using Cohesive Zone Models: Effect of the Cohesive Parameters on the Output of the Simulations," J. Adhes., vol. 88, no. 4-6, pp. 513-533, Apr. 2012.

[39] T. E. A. Ribeiro, R. D. S. G. Campilho, L. F. M. da Silva, and L. Goglio, "Damage analysis of compositealuminium adhesively-bonded single-lap joints,” Compos. Struct., vol. 136, pp. 25-33, Feb. 2016.

[40] W. Jiang and P. Qiao, “An improved four-parameter model with consideration of Poisson's effect on stress analysis of adhesive joints," Eng. Struct., vol. 88, pp. 203-215, Apr. 2015.

[41] J. O. S. Silva, R. D. S. G. Campilho, and R. J. B. Rocha, "Crack growth analysis of adhesively-bonded stepped joints in aluminium structures," J. Brazilian Soc. Mech. Sci. Eng., vol. 40, no. 11, p. 540, Nov. 2018.

[42] D. L. Alves, R. D. S. G. Campilho, R. D. F. Moreira, F. J. G. Silva, and L. F. M. da Silva, "Experimental and numerical analysis of hybrid adhesively-bonded scarf joints," Int. J. Adhes. Adhes., vol. 83, pp. 87-95, Jun. 2018. 


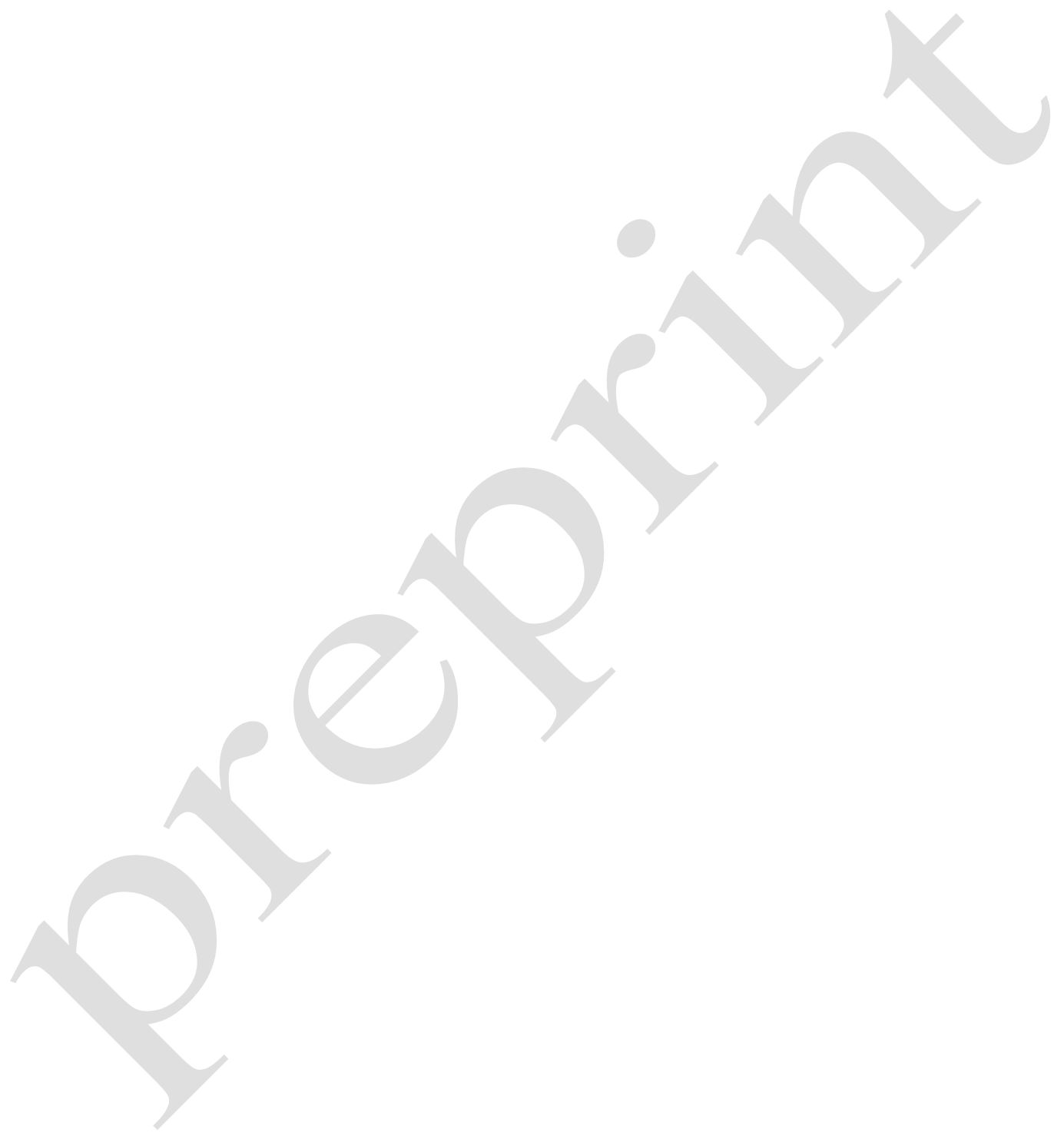

